\title{
Effect of Allium sativum on the Carbohydrate Metabolism of Haemonchus contortus
}

\author{
L. Veerakumari ${ }^{1}$, N. Chitra ${ }^{2}$ \\ Post graduate and Research Department of Zoology, Pachaiyappa's College, Chennai -600030, India
}

\begin{abstract}
Gastrointestinal (GI) nematode infections in small ruminants are widely prevalent in Indian sub continent and leads to heavy economic losses to meat and wool industries worldwide, among which a nematode, Haemonchus contortus account for more losses in livestock. In the present investigation, the effect of Allium sativum ethanol extract (AsEE) on the enzymes of carbohydrate metabolism viz. pyruvate kinase (PK), phosphoenolpyruvate carboxykinase (PEPCK), lactate dehydrogenase (LDH), malate dehydrogenase (MDH), fumarate reductase (FR) and succinate dehydrogenase (SDH) of Hamonchus contortus was studied in vitro. The parasites were incubated in five different sub-lethal concentrations of AsEE viz. 0.005, 0.01, 0.05, 0.1 and $0.5 \mathrm{mg} / \mathrm{ml}$ for 2,4 and 8h. The activity of all the enzymes of carbohydrate metabolism was assayed using standard procedures. The enzyme activity was expressed in terms of protein. The data obtained were analyzed statistically. AsEE significantly inhibited the enzymes of carbohydrate metabolism and the percentage of inhibition was dose and time dependent. Impairment of carbohydrate metabolism in parasitic helminths may be disastrous since they depend almost entirely on it for their energy supply. Consequently, the energy deprived parasite unable to sustain them in situ may be expelled from the host, Hence, AsEE can be used as anthelmintic drug to control haemonchosis.
\end{abstract}

Keywords: Allium sativum, Haemonchus contortus, Phosphoenolpyruvate carboxykinase, Pyruvate kinase, Lactate dehydrogenase, Malate dehydrogenase, Fumarate reductase, Succinate dehydrogenase.

\section{Introduction}

Parasitism is an important limiting factor responsible for deteriorating the health and productivity of livestock and it is considered as economically important diseases of livestock [1]. Parasitic infestations exert adverse effects on the animals [2]. These effects are varied and more pronounced in sheep and goats compared to those seen in other species of livestock [3]. Many species of parasites are seen in sheep and goats and usually include Haemonchus, Oesophagostomum, Ostertagia, Cchabertia, Nematodirus, Trichuris, Moniezia and Fasciola. The most important of these is Haemonchus contortus [4]. H. contortus are the most damaging gastrointestinal worms for livestock in tropical and subtropical regions, particularly for sheep and goats. Both the larvae and the adults feed on blood and cause a considerable damage to the stomach tissues. Haemonchosis caused by $H$. contortus, a common health hazard in small ruminants in India [5] and is responsible for under productivity of the animals [6]. Control of gastrointestinal helminths by use of synthetic anthelmintics has inherent challenges to the poor farmers of developing countries [7]. Furthermore, continuous usage of conventional anthelmintics leads to development of resistance, presence of residues in meat and milk with associated high environmental impact [8]. Resistance of $H$. contortus to ivermectin and benzimidazoles has been reported, the parasite the occurrence being significantly higher in sheep than in goats $[9,10]$. Anthelmintic resistance and other associated shortcomings of conventional drugs has necessitated search for alternative herbal remedies [11] such as medicinal plants. For centuries, medicinal plants have been used to combat parasitism and in many parts of the world are still used for this purpose. The use of medicinal plants for the prevention and treatment of gastro-intestinal parasitism has its origin in ethno veterinary medicine [12].

\section{Background of the Study}

Medicinal plants have played a key role in world health. They are distributed worldwide, but they are most abundant in tropical countries. It is estimated that about $25 \%$ of all modern medicines are directly or indirectly derived from higher plants [13]. Medicinal plants constitute a source of raw materials for both traditional systems of medicine and modern medicine. Nowadays, plant materials are employed throughout the industrialized and developing countries as home remedies, over the counter drugs, and ingredients for the pharmaceutical industry. A large number of plant products are being used to combat gastro-intestinal parasites of livestock and also humans [14-20]. Allium sativum, commonly known as garlic, is one of the species belonging to the family Alliaceae. The anthelmintic activity of $A$. sativum against common intestinal parasites, including Ascaris lumbricoides and hookworms was reported by Riggs and Lamm [21]. Various researchers have reported that oil of $A$. sativum has possessed anthelmintic activity [22-25]. The pharmacological properties of garlic are strictly associated with presence of such chemical compounds as aromatic sulphur-based compounds, phenolic compound (phenolic acids, flavonoids), polysaccharide and protein [26, 27]. In the present investigation effect of Allium sativum on the carbohydrate metabolism of $H$. contortus was studied. Carbohydrate metabolism is used to gauge the anthelmintic property of a plant product against the parasites in vitro conditions. Carbohydrate is an essential energy source in all adult parasitic helminths. Glucose is very important for many helminths inhabiting the alimentary tract and glycogen is the most common polysaccharide reserve in helminths that exists in environments of low $\mathrm{O}_{2}$ tension [28-30]. Helminth parasites depend predominantly on anaerobic energy metabolism, whether or not they exist in nature in environments with low $\mathrm{O}_{2}$ tension [31,32]. Glucose degradation involves the formation of phosphoenolpyruvate 


\section{International Journal of Science and Research (IJSR) \\ ISSN (Online): 2319-7064}

Index Copernicus Value (2013): 6.14 | Impact Factor (2015): 6.391

(PEP) by the classical Embden-Meyerhof scheme, but differs from the vertebrate pattern by the subsequent fixation of $\mathrm{CO}_{2}$. PEP can either be carboxylated by phosphoenolpyruvate carboxykinase (PEPCK) to oxaloacetate (OAA), or dephosphorylated by pyruvate kinase (PK) to pyruvate. Pyruvate so formed comes under the influence of lactate dehydrogenase (LDH) resulting in the formation of lactate. OAA is rapidly converted to malate by malate dehydrogenase (MDH). The malate permeates into the mitochondrion; once inside, a redox dismutation occurs. Fumarase (FM) and malic enzyme (ME) compete for malate, the common substrate, and produce fumarate and pyruvate respectively. Fumarate is further catabolised to succinate via a fumarate reductase complex. Decarboxylation of both pyruvate and succinate results in the final end products of acetate and propionate respectively [33]. Energetically PEPsuccinate pathway is considered more profitable than PEPacetate pathway. Considering the importance of carbohydrates in helminths, the present investigation was carried out to assess the anthelmintic potential of $A$. sativum ethanol extract based on its effect on PK, PEPCK, LDH, MDH, FR and SDH of $H$. contortus

\section{Materials and Methods}

\subsection{Collection and in vitro maintenance of $\boldsymbol{H}$. contortus}

Adult female $H$. contortus were collected from the abomasum of sheep, slaughtered at Perambur slaughter house, Chennai. The worms were washed in physiological saline and maintained in Hedon-Fleig solution $(\mathrm{pH} 7.0)$ at $37^{\circ}$, which is the best medium for in vitro maintenance [34].

\subsection{Preparation of plant extract}

The bulbs of Allium sativum was collected made into paste and soaked serially in hexane, chloroform, ethyl acetate, ethanol and water in an aspirator bottle and extracted by cold percolation method after $48 \mathrm{~h}$ [35]. The filtrate was collected by passing the mixture through Whatman filter paper No.1 and concentrated by using Rotary Evaporator (EQUITRON). The concentrated extracts were dried to remove the solvents using Lyodel freeze Dryer (DELVAC, Chennai).

\subsection{Sample preparation}

Adult $H$. contortus were incubated in $0.005,0.01,0.05,0.1$ and $0.5 \mathrm{mg} / \mathrm{ml}$ concentrations of $A s \mathrm{EE}$ for 2, 4 and 8h. Simultaneously, control was also maintained in Hedon-Fleig solution without the plant extract. After incubation, the parasites were rinsed in distilled water. The parasites were weighed wet and a $10 \%(\mathrm{~W} / \mathrm{V})$ homogenate was prepared by homogenizing the worms in ice-cold $0.25 \mathrm{M}$ sucrose solution containing $0.15 \mathrm{M}$ Tris- $\mathrm{HCl} \quad(\mathrm{pH}-7.5)$ using a tissue homogenizer in an ice-bath. This homogenate was centrifuged at $1000 \mathrm{rpm}$ for $10 \mathrm{~min}$ and the sediment containing the cellular particles viz. nucleus and other organelles were discarded. The supernant was used as the enzyme source. The cytosolic and mitochondrial fractions of H. contortus were prepared following the method of Fry et al. [36].

\subsection{Enzyme assay:}

The enzyme PK and PEPCK activities in the cytosolic fraction were assayed following the method of McManus and Smyth [37]. The oxidation and reduction reactions of $\mathrm{LDH}$ activity was assayed following the procedure of Yoshida and Freese [38]. MDH catalysing the oxidation of malate and reduction of OAA was assayed in both the cytosolic and mitochondrial fractions following the method of Yoshida [39]. FR activity was assayed as detailed by Sanadi and Fluharty [40]. SDH activity was assayed according to the method of Singer [41]. The enzyme activity was expressed in terms of protein content. Protein in the sample was determined by the method of Lowry et al. [42].

\subsection{Statistical analyses}

The experimental results were expressed as mean \pm standard deviation. Each value is expressed as mean of triplicate experiments. Statistical analyses were performed by ANOVA using SPSS version 20 for different concentration of ethanol extract of $A$. sativum.

\section{Results and Discussion}

AsEE inhibited the activity of the enzymes such as PK, PEPCK, LDH, MDH, FR and SDH involved in carbohydrate metabolism at different concentrations and period of exposure (Tables 1-5). Phophoenolpyruvate carboxykinase (PEPCK) and pyruvate kinase (PK) play key roles in helminth energy metabloism. PEPCK is the most active $\mathrm{CO}_{2}$ fixing enzyme and this reaction serves as the link between the glycolytic pathway and the TCA cycle [43]. Therefore, PK and PEPCK are the main targets for therapeutic interference. AsEE significantly inhibited the PK and PEPCK activities of $H$. contortus (Table 1 ). The inhibition of PK activity results in reduced production of pyruvate and the inhibition of PEPCK arrests the PEP-lactate or acetate/PEP-succinate or propionate pathways [44]. This leads to the impairment of energy yielding process deprives the parasite of its ATP production. Reduced production of ATP proves fatal to the parasites. The inhibition of PK and PEPCK activities treated with anthelmintics in other helminths are on record [45-47]. Navaneetha Lakshmi and Veerakumari [48] reported the inhibitory effect on the PK and PEPCK activities in Haemonchus contortus treated with Allium sativum.

The action of PK on PEP results in the production of pyruvate. It is evident from the prsesnt investigation that AsEE inhibited the LDH catalysing both the lactate oxidation and pyruvate reduction (Table 2). The inhibitory effect of PZQ and LEV on LDH activity of $C$. cotylophorum has been reported by Veerakumari and Munuswamy [49]. Similar inhibitory effect of $A$. sativum on the LDH activity catalysing both the oxidation and the reduction reactions in $H$. contortus has been reported by Veerakumari and Navaneetha Lakshmi [34].

$\mathrm{MDH}$ is a complex regulator of energy metabolism [50,51] and is involved in both anaerobic and aerobic respiration [52]. AsEE significantly inhibited the cytoplasmic $\mathrm{MDH}$ 


\section{International Journal of Science and Research (IJSR) \\ ISSN (Online): 2319-7064 \\ Index Copernicus Value (2013): 6.14 | Impact Factor (2015): 6.391}

(cMDH) and mitochondrial MDH (mMDH) catalysing both the oxidation and reduction reactions in $H$. contortus (Table $3 \& 4)$. This inhibition indicates an overall inhibition of the glycolytic pathway, with a consequent decline in the energy reserves of the helminths. Drug-induced inhibition of $\mathrm{MDH}$ activity was observed in $F$. hepatica, F. gigantica, F. buski and $P$. explanatum [52, 53] and several other helminth parasites [47, 54-56]. Similar inhibitory effect of aqueous extracts of $A$. sativum on the cMDH and mMDH activity of $H$. contortus was reported by Lakshmi and Veerakumari [49].

In the present study, AsEE inhibited the FR and SDH activity of $H$. contortus (Table 5). Inhibition of FR is vital, because it plays a key role in the energy metabolism of most parasitic helminths. Similar with the present studies, Satoshi et al [57] reported selective toxicity and inhibitory effect of nafuredin, a novel compound isolated from Aspergillus nigers. The FR activity of $H$. contortus was also inhibited by other drugs such as tetramisole, thiabendazole, cambendazole, mebendazole, morantel tartrate and disophenol $[58,59,30]$.

Succinate is the major fermentation product in a number of intestinal helminths $[60,61]$. On investigating the activity of $\mathrm{SDH}$ in $H$. contortus, a significant decrease in the enzyme activity of AsEE-treated worms was noted. Skuce and Fairweather's [62] findings also explain that SDH inhibition by anthelmintics could prevent the utilization of the chemical energy derived from electron transport for the net phosphorylation of ADP to ATP and deprive the parasite of its normal source of energy. The inhibition of SDH activity in Heterakis, Trichuris, Ascardia, Chabertia, Bunostomum and
Nematoderius by tetramisole has been reported by Van den Bossche and Janssen [63]. Inhibition of SDH activity induced by synthetic drugs has been reported in $H$. contortus [59,64], Aspicularis tetraptera and A.summ [65].

The inhibition of the enzymes of metabolism of $H$. contortus by Allium sativum was reported by Navaneetha lakshmi and Veerakumari [66]. Inhibition of the enzymes, PK, PEPCK, $\mathrm{LDH}, \mathrm{MDH}, \mathrm{FR}$ and SDH activity by AsEE impairs the energy metabolism of the parasites resulting in less production of ATP. Consequently, the energy deprived parasite unable to sustain themselves in situ may be expelled from the host. The results of the present investigation revealed that $A s E E$ could be used as a potential phytotherapeutic drug to control $H$. contortus infection in livestock.

\section{Conclusion}

The present study revealed that $A$. sativum ethanol extract have anthhelmintic activity against Haemonchus contortus. From these studies, it could be concluded that the bulbs of $A$. sativum are the good traditional medicines for helmintic infections.

\section{Acknowledgements}

We gratefully acknowledge University Grant commission (UGC), for funding this project.

Table 1: Effect of AsEE on PK and PEPCK activity of H. contortus

\begin{tabular}{|c|c|c|c|c|c|c|}
\hline \multirow{3}{*}{$\begin{array}{l}\text { Conc. } \\
\text { mg/ml* }\end{array}$} & \multicolumn{6}{|c|}{$\begin{array}{c}\% \text { inhibition (mean } \pm \text { SD of } n=5) \text { at various } \\
\text { periods of incubation** }\end{array}$} \\
\hline & $2 \mathrm{~h}$ & $4 \mathrm{~h}$ & $8 \mathrm{~h}$ & \begin{tabular}{|l|l|}
$\mathbf{2 h}$ & \\
\end{tabular} & & $8 \mathrm{~h}$ \\
\hline & \multicolumn{3}{|c|}{ PK } & \multicolumn{3}{|l|}{ PEPCK } \\
\hline 0.005 & $18.85 \pm 0.002$ & $44.83 \pm 0.002$ & $60.78 \pm 0.002$ & $20.71 \pm 0.004$ & $39.88 \pm 0.003$ & $62.24 \pm 0.003$ \\
\hline 0.01 & $23.74 \pm 0.003$ & $49.12 \pm 0.002$ & $67.06 \pm 0.002$ & $21.56 \pm 0.003$ & $46.04 \pm 0.003$ & $66.52 \pm 0.002$ \\
\hline 0.05 & $33.49 \pm 0.013$ & $52.94 \pm 0.002$ & $73.94 \pm 0.002$ & $35.25 \pm 0.007$ & $51.37 \pm 0.001$ & $71.53 \pm 0.002$ \\
\hline 0.1 & $39.60 \pm 0.008$ & $59.86 \pm 0.001$ & $76.47 \pm 0.009$ & $37.10 \pm 0.003$ & $56.47 \pm 0.002$ & $72.92 \pm 0.002$ \\
\hline 0.5 & $42.17 \pm 0.004$ & $63.92 \pm 0.003$ & $82.89 \pm 0.002$ & $39.67 \pm 0.024$ & $63.00 \pm 0.002$ & $82.09 \pm 0.013$ \\
\hline \multicolumn{7}{|c|}{$\begin{array}{l}* \text { Inhibitory effects of the extracts among the different concentrations of the respective plants are duration of incubation } \\
(\mathrm{P}<0.05) \text { using Duncan principle comparisons. } \\
* * \text { Inhibitory effects of the extracts among the different hours of incubation is significantly different for each concentration o } \\
\text { the respective plants }(\mathrm{P}<0.01) \text { Duncan principle comparisons. }\end{array}$} \\
\hline
\end{tabular}

Table 2: Effect of AsEE on LDH activity of H. contortus

\begin{tabular}{|c|c|c|c|c|c|c|}
\hline \multirow{3}{*}{$\begin{array}{l}\text { Conc. } \\
\mathrm{mg} / \mathrm{ml}^{*}\end{array}$} & \multicolumn{6}{|c|}{$\begin{array}{c}\% \text { inhibition (mean } \pm \text { SD of } n=5) \text { at various } \\
\text { periods of incubation } * *\end{array}$} \\
\hline & $2 \mathrm{~h}$ & $4 h$ & $8 \mathrm{~h}$ & \begin{tabular}{|c|c|}
$\mathbf{2 h}$ & \\
\end{tabular} & $4 \mathrm{~h}$ & $8 h$ \\
\hline & \multicolumn{3}{|c|}{ Oxidation } & \multicolumn{3}{|l|}{ Reduction } \\
\hline 0.005 & $16.35 \pm 0.002$ & $37.47 \pm 0.004$ & $56.67 \pm 0.002$ & $14.62 \pm 0.002$ & $33.79 \pm 0.003$ & $47.86 \pm 0.002$ \\
\hline 0.01 & $21.15 \pm 0.003$ & $42.22 \pm 0.004$ & $61.82 \pm 0.003$ & $22.38 \pm 0.002$ & $37.78 \pm 0.002$ & $51.40 \pm 0.002$ \\
\hline 0.05 & $27.76 \pm 0.003$ & $43.57 \pm 0.002$ & $65.33 \pm 0.002$ & $28.85 \pm 0.002$ & $43.86 \pm 0.002$ & $54.10 \pm 0.003$ \\
\hline 0.1 & $31.88 \pm 0.002$ & $49.11 \pm 0.003$ & $70.75 \pm 0.002$ & $31.69 \pm 0.003$ & $49.48 \pm 0.002$ & $59.50 \pm 0.003$ \\
\hline 0.5 & $32.69 \pm 0.003$ & $53.78 \pm 0.001$ & $76.36 \pm 0.002$ & $38.13 \pm 0.002$ & $57.33 \pm 0.002$ & $70.54 \pm 0.002$ \\
\hline \multicolumn{7}{|c|}{$\begin{array}{l}* \text { Inhibitory effects of the extracts among the different concentrations of the respective plants are duration of incubation } \\
(\mathrm{P}<0.05) \text { using Duncan principle comparisons. } \\
* * \text { Inhibitory effects of the extracts among the different hours of incubation is significantly different for each concentration of } \\
\text { the respective plants }(\mathrm{P}<0.01) \text { Duncan principle comparisons. }\end{array}$} \\
\hline
\end{tabular}




\section{International Journal of Science and Research (IJSR) \\ ISSN (Online): 2319-7064}

Index Copernicus Value (2013): 6.14 | Impact Factor (2015): 6.391

Table 3: Effect of AsEE on cMDH activity of H. contortus

\begin{tabular}{|c|c|c|c|c|c|c|}
\hline \multirow{3}{*}{$\begin{array}{l}\text { Conc. } \\
\mathrm{mg} / \mathrm{ml}{ }^{*}\end{array}$} & \multicolumn{6}{|c|}{$\begin{array}{c}\% \text { inhibition (mean } \pm \text { SD of } n=5) \text { at various } \\
\text { periods of incubation } * *\end{array}$} \\
\hline & $2 \mathrm{~h}$ & 4h & $8 h$ & \begin{tabular}{|l|l|}
$2 h$ & $4 h$ \\
\end{tabular} & & $8 \mathrm{~h}$ \\
\hline & \multicolumn{3}{|c|}{ Oxidation } & \multicolumn{3}{|l|}{ Reduction } \\
\hline 0.005 & $19.66 \pm 0.002$ & $41.15 \pm 0.011$ & $65.95 \pm 0.008$ & $17.75 \pm 0.004$ & $40.79 \pm 0.010$ & $56.27 \pm 0.011$ \\
\hline 0.01 & $23.96 \pm 0.003$ & $46.66 \pm 0.003$ & $70.29 \pm 0.009$ & $19.03 \pm 0.003$ & $41.46 \pm 0.012$ & $62.51 \pm 0.005$ \\
\hline 0.05 & $25.99 \pm 0.002$ & $49.47 \pm 0.002$ & $71.11 \pm 0.005$ & $28.03 \pm 0.012$ & $50.72 \pm 0.007$ & $63.91 \pm 0.006$ \\
\hline 0.1 & $28.96 \pm 0.003$ & $52.94 \pm 0.003$ & $72.14 \pm 0.004$ & $30.14 \pm 0.012$ & $54.07 \pm 0.008$ & $71.89 \pm 0.004$ \\
\hline 0.5 & $35.48 \pm 0.002$ & $64.44 \pm 0.002$ & $79.74 \pm 0.002$ & $37.42 \pm 0.016$ & $63.58 \pm 0.003$ & $80.00 \pm 0.024$ \\
\hline \multicolumn{7}{|c|}{$\begin{array}{l}* \text { Inhibitory effects of the extracts among the different concentrations of the respective plants are duration of incubation } \\
(\mathrm{P}<0.05) \text { using Duncan principle comparisons. } \\
* * \text { Inhibitory effects of the extracts among the different hours of incubation is significantly different for each concentration of } \\
\text { the respective plants }(\mathrm{P}<0.01) \text { Duncan principle comparisons. }\end{array}$} \\
\hline
\end{tabular}

Table 4: Effect of AsEE on mMDH activity of H. contortus.

\begin{tabular}{|c|c|c|c|c|c|c|}
\hline \multirow{3}{*}{$\begin{array}{l}\text { Conc. } \\
\mathrm{mg} / \mathrm{ml}^{*}\end{array}$} & \multicolumn{6}{|c|}{$\begin{array}{c}\% \text { inhibition (mean } \pm \text { SD of } n=5) \text { at various } \\
\text { periods of incubation** }\end{array}$} \\
\hline & $2 \mathrm{~h}$ & 4h & $8 h$ & \begin{tabular}{|l|l|}
$2 h$ & $4 h$ \\
\end{tabular} & & $8 \mathbf{h}$ \\
\hline & \multicolumn{3}{|c|}{ Oxidation } & \multicolumn{3}{|l|}{ Reduction } \\
\hline 0.005 & $20.43 \pm 0.003$ & $36.81 \pm 0.004$ & $66.15 \pm 0.002$ & $19.23 \pm 0.002$ & $35.80 \pm 0.004$ & $56.67 \pm 0.003$ \\
\hline 0.01 & $23.30 \pm 0.003$ & $45.83 \pm 0.002$ & $67.13 \pm 0.002$ & $21.25 \pm 0.002$ & $37.39 \pm 0.003$ & $59.30 \pm 0.002$ \\
\hline 0.05 & $30.82 \pm 0.002$ & $51.85 \pm 0.002$ & $69.78 \pm 0.002$ & $25.00 \pm 0.002$ & $41.15 \pm 0.002$ & $61.00 \pm 0.002$ \\
\hline 0.1 & $35.13 \pm 0.002$ & $54.49 \pm 0.001$ & $74.62 \pm 0.0007$ & $28.75 \pm 0.002$ & $48.64 \pm 0.001$ & $66.87 \pm 0.002$ \\
\hline 0.5 & $42.29 \pm 0.003$ & $56.90 \pm 0.002$ & $78.85 \pm 0.0007$ & $35.71 \pm 0.001$ & $51.85 \pm 0.0007$ & $70.83 \pm 0.001$ \\
\hline \multicolumn{7}{|c|}{$\begin{array}{l}\text { * Inhibitory effects of the extracts among the different concentrations of the respective plants are duration of incubation } \\
(\mathrm{P}<0.05) \text { using Duncan principle comparisons. } \\
* * \text { Inhibitory effects of the extracts among the different hours of incubation is significantly different for each concentration of } \\
\text { the respective plants }(\mathrm{P}<0.01) \text { Duncan principle comparisons. }\end{array}$} \\
\hline
\end{tabular}

Table 5: Effect of AsEE on FR and SDH activity of H. contortus

\begin{tabular}{|c|c|c|c|c|c|c|}
\hline \multirow{3}{*}{$\begin{array}{l}\text { Conc. } \\
\text { mg/ml* }\end{array}$} & \multicolumn{6}{|c|}{$\begin{array}{c}\% \text { inhibition (mean } \pm \text { SD of } n=5) \text { at various } \\
\text { periods of incubation } * *\end{array}$} \\
\hline & $2 \mathbf{h}$ & $4 \mathrm{~h}$ & $8 h$ & \begin{tabular}{|l|l|}
$2 h$ & $4 h$ \\
\end{tabular} & & $8 \mathbf{h}$ \\
\hline & \multicolumn{3}{|c|}{ FR } & \multicolumn{3}{|l|}{ SDH } \\
\hline 0.005 & $21.32 \pm 0.014$ & $50.76 \pm 0.002$ & $66.29 \pm 0.003$ & $18.27 \pm 0.002$ & $51.45 \pm 0.002$ & $62.60 \pm 0.015$ \\
\hline 0.01 & $26.14 \pm 0.002$ & $55.68 \pm 0.004$ & $72.40 \pm 0.002$ & $27.08 \pm 0.004$ & $52.00 \pm 0.006$ & $64.56 \pm 0.013$ \\
\hline 0.05 & $31.82 \pm 0.002$ & $57.32 \pm 0.003$ & $74.65 \pm 0.003$ & $37.50 \pm 0.002$ & $58.10 \pm 0.002$ & $70.14 \pm 0.031$ \\
\hline 0.1 & $40.34 \pm 0.002$ & $60.61 \pm 0.002$ & $78.71 \pm 0.002$ & $45.31 \pm 0.003$ & $60.00 \pm 0.002$ & $78.00 \pm 0.01$ \\
\hline 0.5 & $41.56 \pm 0.002$ & $64.55 \pm 0.002$ & $86.61 \pm 0.002$ & $46.95 \pm 0.002$ & $65.71 \pm 0.002$ & $86.25 \pm 0.002$ \\
\hline
\end{tabular}

\section{References}

[1] Perry, B. D., Randolph, T. F., McDermott, J. J., Sones, K. R. and Thornton, P. K., 2002. Investing in animal health research to alleviate poverty. International Livestock Research Institute, Nairobi, Kenya, pp: 148.

[2] Rehman, K. U., Javed, K., Tunio, M. T. and Kuthu, Z. H., 2009. Passive survalance of Gastro intestinal parasites in buffaloes of mandi Bahauddin and Gujrat districts of the Punjab. Journal of Animal and Plant Science, 19(1): 17-19.

[3] Iqbal, Z., Akhtar, M., Khan, M. N., and Riaz, M., 1993. Prevalence and economic significance of haemonchosis in sheep and goats slaughtered at Faisalabad abattoir. Pakistan J. Agric. Sci., 30: 51-3.

[4] Husnain, H. U. and Usmani, R. H., 2006. Livestock of Pakistan. 1st Ed. Livestock Foundation, Islamabad, Pakistan, pp: 140-141.
[5] Gupta, R. P., Yadav, C. L. and Ruprath, N. S., 1988. Epidemiology of ovine helminthiasis in Haryana. India Tropical Animal Health Production, 20: 23-29.

[6] Yadav, C. L. and Uppal, R. P., 1992. Leva misole against Haemonchus contortus. Veterinary Record, 130: 228

[7] Marley, C. L., Cook, R., Barrett, J., Kea tinge, R. and Lampkin, N. M., 2003. The effect of bird foot trefoil (Lotus corniculatus) and chicory (Cichorium intybus) on parasite intensities and performance oflambs naturally infected with Helminth parasites. Vet. Parasitol, 112, 147-155.

[8] Echevaria, F. A., Amour, J., Borba, M. F., Duncal, L., 2007. Response to ivermectin treatment of parasiticstages of Haemonchus conturtus resistance or susceptible to ivermectin, J. Parasitol., 78(5): 894-8

[9] Peter J Walker and Chandrawathani, P., 2005. Haemonchus contortus: Parasite problem No.1 Tropics-Polar Circle. Problems and prospects for 


\section{International Journal of Science and Research (IJSR) \\ ISSN (Online): 2319-7064}

Index Copernicus Value (2013): 6.14 | Impact Factor (2015): 6.391

control based on epidemiology, tropical Biomedicine, 22(2): 131-137.

[10] William, J. and Blackhall, 1998. Genetic variation and multiple mechanisms of anthelmintic resistance to $H$. Contortus. PhD Thesis, MacGill University, Quebec, Canada.

[11] Oliveira, L. M. B., Bevilaqua, C. M. L., Costa, C. T. C., Macedo, I. T. F., Barros, R. S., Rodrigues, A. C. M., Camurc $_{\mathrm{s}} \mathrm{a}-$ Vasconcelos, A. L. F., Morais, S. M., Lima, Y. C., Vieira, L. S and Navarro, A. M. C., 2009. Anthelmintic activity of Cocos nucifera L. against sheep gastrointestinal nematodes, Veterinary Parasitology, 159:55-59.

[12] Athanasiadou, S., Githiori, J. and Kyriazakis, I., 2007. Medicinal plants for helminth parasite control: facts and fictions. Animal, 1(9): 1392-1400.

[13] WHO, 2005. Global Atlas of Traditional, Complementary and Alternative Medicine. 2 (1) contain text and Vol. 2, maps. World Health Organization, Geneva.

[14] Kozan, E., Kupeli, E. and Yesilada, E., 2006. Evaluation of some plants used in Turkish folk medicine against parasitic infections for their in vivo anthelmintic activity. J. Ethnopharmacol., 108: 211216.

[15] Lyndem, L. M., Tandon, V. and Das, B., 2008. Anthelmintic efficacy of medicinal plants from Northeast India against hookworms: an in vitro study on Ancylostoma cylanicum. Pharmacologyonline, 3: 697-707.

[16] Roy, B., Dasgupta, S. and Tandon, V., 2008. Ultrastructural observations on tegumental surface of Raillietina echinobothrida and its alterations caused by root-peel extract of Millettia pachycarpa. Microsc. Res. Tech., 71: 810-815.

[17] Al-Shaibani, I. R. M., Phulan, M. S. and Shiekh, M., 2009. Anthelmintic activity of Fumaria parviflora (Fumariaceae) against gastrointestinal nematodes of sheep. Int. J. Agr. Biol., 11: 431-436.

[18] Kosalge, S. B. and Fursule, R. A., 2009. Investigation of in vitro anthelmintic activity of Thespesia lampas (Cav.). Asian J. Pharm. Clin. Res., 2(2): 69-71.

[19] Challam, M., Roy, B. and Tandon, V., 2010. Effect of Lysimachia ramose (Primulaceae) on helminth parasites: motility, mortality and scanning electron microscopic observations on surface topography. Vet. Parasitol., 169: 214-218.

[20] Manolaraki, F., Sotiraki, S., Stefanakis, A., Skampardonis, V., Volanis, M. and Hoste, H., 2010. Anthelmintic activity of some Mediterranean browse plants against parasitic nematodes. Parasitol., 137: 685-696.

[21] Riggs, D. R. and Lamm, D. L., 1997. Garlic: Treatment for cell carcinoma. 1666-1690.

[22] Hoppe, H. A., 1975. Drogenkunde, Vol. I, Angiosperms, $8^{\text {th }}$ ed. Walter De Gruyter, Berlin.

[23] Nadkarni, K. M., 1976. Indian Materia Medica, Vol. I \& II. Popular Prakashan Private Limited, Bombay, India.

[24] Perry, L. M., 1980. Medicinal Plants of East and Southeast Asia. M.I.T. Press, London.
[25] Kirtikar, K. R. and Basu, B. D., 1981. Indian Medicinal Plants. Part II, Indian Press.

[26] Bianchini, F. and Vainio, H., 2001. Allium vegetables and organosulphur compounds: do they help prevent cancer. Environmental Health Perspectives, 109(9): 893-902.

[27] Nishimura, H., Higuchi, O. and Tateshita, K., 2004. Antioxidative activity of sulphur-containing compounds in Allium species for human LDL oxidation in vitro. Biofactors, 21: 277.

[28] Ward, P.F.V., 1974. The metabolism of glucose by Haemonchus contortus in vitro. Parasitology, 69: 175190.

[29] Ward, P. F. V., 1982. Aspects of helminth mechanism. Parasitology, 84: 177-194.

[30] Kaur, R. and Sood, M. L., 1983. The effects of DLtetramisole and rafoxanide on tricarboxylic acid cycle enzymes of Haemonchus contortus, in vitro Parasitol., 13: 333-340.

[31] Von Brand, T., 1974. The biochemistry of helminths Zettschriftfur Parasitekunde, 45: 109-124.

[32] Bryant, C., 1975. Carbon dioxide utilization and the regulation of respiratory metabolic pathway in parasitic helminths. Advances in Parasitology, 13: 35-69. Academic Press, New York.

[33] Barrett, J., 1981. Biochemistry of Parasitic Helminths. Macmillan Press, London. pp.308.

[34] Veerakumari, L and Navaneetha Lakshmi, K., 2006. In vitro efficacy of Allium sativum on lactate dehydrogenase activity of Haemonchus contortus. Journal of yeterinary parasitology., 20 (1): 93-96.

[35] Harborne, J. B., 1998. Phytochemical Methods: A Guide to Modern Techniques of Plant Analysis Chapman Hall,Londan, 3rd Edition, p. 27-70.

[36] Fry, M., Bazil, C. and Jenkins, D. C., 1983. A comparison of mitochondrial electron transport in the intestinal parasitic nematodes Nippostrongylus brasiliensis and Ascardia galli. Comparative Biochemistry and Physiology, 75B: 451-453.

[37] McManus, D. P. and Smyth, J. D., 1982. Intermediary Carbohydrate metabolism in protoscoleces of Echinococcus granulosus (horse and sheep strains) and E. multiocularis. Parasitology, 84: 351-366.

[38] Yoshida, A. and Freese, E., 1975. Lactate dehydrogenase from Bacillus subtilis. In: Methods in Enzymology. Wood, W.A. (Ed.), Vol. XLI. Academic press, New York, pp. 304.

[39] Yoshida, A., 1969. L-Malate dehydrogenase from Bacillus subtilis. In: Methods in Enzymology. Lownstein J.M. (Ed.), Vol. XIII, Academic Press, New York, pp: 141-145.

[40] Sanadi, D. R. and Fluharty, A. L., 1963. On the mechanism of oxidative phosphorylation. VII- The energy requiring reduction of pyridine nucleotide by succinate and energy yielding oxidation of reduced pyridine nucleotide by fumarate. Biochemistry, 2: 523 528.

[41] Singer, T. P., 1974. Determination of activity of succinate, $\mathrm{NADH}$, choline and $\alpha$-glycerophosphate dehydrogenase. In: Methods in Biochemical Analysis. 


\section{International Journal of Science and Research (IJSR) \\ ISSN (Online): 2319-7064}

Index Copernicus Value (2013): 6.14 | Impact Factor (2015): 6.391

(Glick, D ed.), Vol. 22, Interscience publications. John Wiley and Son, New York, pp: 133-161.

[42] Lowry, O. H., Rosebrough, N. J., Farr, A. L. and Randall, R. J., 1951. Protein measurement with the Folin phenol reagent. The Journal of Biological Chemistry, 193: 265-275.

[43] Prescott, L. M. and Campbell, J. W., 1965. Phosphenolpyruvate carboxykinase activity and glycogenesis in the flatworm, Hymenolepis diminuta. Comparative Biochemistry and Physiology, 14: 491511.

[44] Bhem, C. A. and Bryant C., 1982.Phosphoenolpyruvate carboxykinase from Fasciola hepatica. Int. J. Parasitol, 12: 271-278 (1982).

[45] Rahman, M. S. and Bryant, C., 1977. Studies of regulatory metabolism in Moniezia expansa: effects of cambendazole and mebendazole. International Journal of Parasitology, 7: 403-409.

[46] Lloyd, G. M. and Barrett, J., 1983. Fasciola hepatica: Inhibition of phosphoenolpyruvate carboxykinase, and end-product formation by quinolinic acid and 3mercaptopicolinic acid. Experimental Parasitology, 56: 259-265.

[47] Srivastava, J. K., Gupta, S. and Katiyar, J. C., 1989. Effects of methyl [5[[4-(2-pyridinyl)-1-piperazinyl] carbonyl]-1H-benzimidazol-2-yl] carbamate on energy metabolism of Ancylostoma ceylanicum and Nippostrongylus brasiliensis. Indian Journal of Expeimental Biology, 27: 735-738.

[48] Navaneetha, L. K. and Veerakumari, L., 2009. Effect of Allium Sativum on the Phosphoenolpyruvate carboxykinase and Pyruvate Kinase Activity of Haemonchus Contortus in vitro. Pharmacognosy Magazine 5 (20): 430- 432.

[49] Veerakumari, L. and Munuswamy, N., 2000. In vitro effect of some anthelmintics on lactate dehydrogenase activity of Cotylophoron cotylophorum (Digenea: Paramphistomidae). Veterinary Parasitology, 91: 129140.

[50] Fodge, D. W., Gracy, R. W. and Harris, B. G., 1972. Studies on enzymes from muscle tissue of Ascaris suum. Biochemistry, Biophysics and Acta, 268: 271284.

[51] Lamperger, W. J. and Harris, D. G., 1976. NAD-malic enzyme. Regulatory properties of the enzyme from Ascaris suum. The Journal of Biological Chemistry, 251: 3599-3602.

[52] Lwin, T. and Probert, A. J., 1975. Effect of certain fasciolicides on malate dehydrogenase activity in Fasciola hepatica: a possible biochemical mode of action of hexachlorophene and oxyclozanide. Journal of Pesticide Science, 6: 121-128.

[53] Probert, A. J., Sharma, R. K., Singh, K. and Saxena, R., 1981. The effect of five fasciolicides on malate dehydrogenase activity and mortality of Fasciola gigantica, Fasciolopsis buski and Paramphistomum explanatum. Journal of Helminthology, 55: 115-122.

[54] Tejada, P., Sanchez-Moreno, M., Monteoliva, M. and Gomez-Banqueri, H., 1987. Inhibition of malate dehydrogenase enzymes by benzimidazole anthelmintics. Veterinary Parasitology, 24: 269-274.
[55] Sanchez-Moreno, M., Ortega, J. E. and Valero, A., 1989. Cellular distribution, purification and electrophoretic properties of malate dehydrogenase in Trichuris ovis and inhibition by benzimidazoles and pyrimidine derivatives. Veterinary Parasitology, 34: 203-211.

[56] Parveen, Sood, M. L. and Soni, G. L., 1992. In vitro anthelmintic effects of rafoxanide on some dehydrogenases of Trichuris globulosa. Ind. J. Parasitol., 16: 183-184.

[57] Satoshi, O., Mura, Hiroko Miyadera, Hideaki Ui, Kazuro Shiomi, Yuuichi Yamaguchi, Rokuro Masuma, Tohru Nagamitsu, Daisuke Takano, Toshiaki Sunazuka, Achim Harder, Heinz Ko lbl, Michio Namikoshii, Hideto Miyoshi, Kimitoshi Sakamoto and Kiyoshi Kita, 2001. An anthelmintic compound, nafuredin, shows selective inhibition of complex I in helminth mitochondria. Proceedings of the National Academy of Sciences, 98 (1): 60-62.

[58] Prichard, R. K., 1970. Mode of action of the anthelmintic thiabendazole in Haemonchus contortus. Nature, 228: 684-685.

[59] Malkin, M. F. and Camacho, R. M., 1972. The effect of thiabendazole on fumarate reductase from thiabendazole-sensitive and resistant Haemonchus contortus. Journal of Parasitology, 58: 845-846.

[60] Bueding, E., 1963. Electron transport and fermentation in Ascaris lumbricoides. In: Control mechanisms in respiration and fermentation (wright, B.ed.) Ronald Press, New York, pp: 167-177.

[61] Saz, H. J. and Bueding, E., 1966. Relationships between anthelmintic effects and biochemical and physiological mechaniusm. The Pharma Review, 18: 871-894.

[62] Skuce, P. J. and Fairweather, I., 1990. The effect of thehydrogen ionophore closantel upon the pharmacology and ultrastructure of the adult liver fluke Fasciola hepatica. Parasitology Research, 76: 241250.

[63] Van den Bossche, H. and Janssen, P. A. J., 1969. The biochemical mechanism of action of the antinematodal drug tetramisole. Biochemical Pharmacology, 18: 3542.

[64] Prichard, R. K., 1973. The fumarate reductase reaction of Haemonchus contortus and the mode of action of some anthelmintics. International Journal of Parasitology, 3: 409-417.

[65] Combley, J. C. W. and Wright, D. J., 1981. Succinate dehydrogenase funarate reductase activity in Spicularis tetraptera and Ascaris suum and the effects of the anthelmintics cambendazole, thiabendazole and levamisole. Indian Journal of parasitology, 11: 79-84.

[66] Navaneetha Lakshmi, K., 2006 Anthelmintic effects of Allium sativum L. and Andrographis paniculata nees, on Haemonchus contortus (Rud, 1803) (Nematoda:Trichostrongylidae). 


\section{Author Profile}

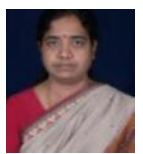

Dr. (Mrs) L. Veerakumari, Associate Professor \& Head, PG \& Research Department of Zoology, Pachaiyappa's College, Chennai, Tamil Nadu, India has thirty five years of teaching and research experience. She has received her $\mathrm{PhD}$ degree from University of Madras, India in 1997. She is a life member of Indian Association for the Advancement of Veterinary Parasitology, Indian society of Parasitology, Indian Association of Biomedical Scientists, Indian Association of physiologists and pharmacologists, Indian Society of education and environment, Indian Association of Science and technology and Indian Science Congress Association. She has authored two books and has published many research papers. She has completed six research projects funded by UGC, DST and TNSCST. She is a Gold medalist and received many best paper awards, MABMS and FABMS Title, Best researcher award, Bharat Jothi award, Ismail oration award and Inducted into the American order of Scientific and technical merit.

Mrs. Chitra. N. is Ph. D. Reasearch Scholar, PG and Research Department of Zoology, Pachaiyappa's College, Chennai - 600 030. Currently she is doing $\mathrm{Ph} . \mathrm{D}$. (Full-time) in the field of veterinary Pasitology under the able guidance of Dr.L.Veerakumari. 